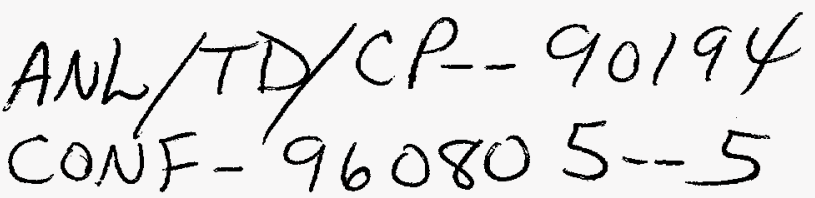

\title{
DYNAMIC RESPONSE OF STEAM-REFORMED, METHANOL-FUELED, POLYMER ELECTROLYTE FUEL CELL SYSTEMS
}

\author{
H. K. Geyer, R. K. Ahluwalia, R. Kumar \\ Argonne National Laboratory \\ 9700 S. Cass Áve. Argonne, IL 60439 \\ TEL: 708-252-5979 \\ FAX: 708-252-4007
}

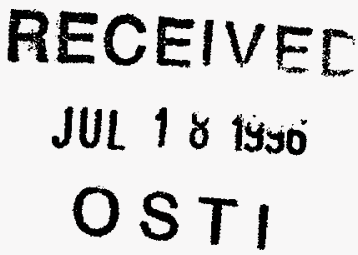

\section{ABSTRACT}

Analytical models have been developed to study the dynamic response of steam-reformed, methanol-fueled, polymer electrolyte fuel cell (PEFC) systems for transportation applications. Attention is focused primarily on the heat transfer effects which are likely to limit rapid response of PEFC systems. Depending on the thermal mass, the heat exchangers and the steam reformer can have time constants of the order of several seconds to many minutes. On the other hand, the characteristic time constants associated with pressure/density disturbances arising from flow rate fluctuations are of the order of milliseconds. In vehicular applications, the response time of the turbomachinery, which is determined by the rotational inertia, can be of the order of seconds or less.

The dynamic reformer model has been used to examine the methanol conversion efficiency and the thermal performance during a cold start. Response times are determined to achieve $50-100 \%$ of the steady-state methanol conversion for two catalyst tube diameters. The thermal performance is considered in terms of the approach to steady-state temperature, possibility of catalyst overheating, and the penalty in system efficiency incurred during the start-up time.

For the complete reference PEFC system various turn-down scenarios were simulated by varying the relative rates of change of fuel cell loading and system flows. It is shown that depending on the relative rates of cell loading changes to flow rate changes overheating of the catalyst can occur due to excess heat transfer in the reformer preheater. This can be controlled by an additional water quench between the catalyst bed and preheater, but only if the flow rate change is sufficiently fast relative to the load changes.

\section{INTAODUCTION}

Fuel cells, especially polymer electrolyte fuel cells (PEFC), may become a viable alternative to today's internal combustion (IC) engines for vehicular applications. The PEFC is powered by a hydrogen rich gas stream which can be provided either directly by use

DISTAIBUTION OF THIS DOCUMENT IS UNLIMTED

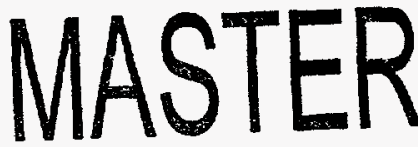

of hydrogen fuel or by reforming a hydrocarbon. Reformers can make use of partial oxidation or steam reforming techniques. The latter involve endothermic reactions and therefore require some form of heat exchange to keep the process working. Heat exchange processes are generally much slower than the response that may be obtained from the fuel cell itself or even from other turbo machines used within the fuel cell system. Thus, the overall speed at which the fuel cell system can adapt to changing loads may well be governed by the response of the reformer and heat exchange processes.

In general, there are several time constants within a fuel cell system. These can be separated into several categories. The first would be the extremely fast dynamics of pressure/density disturbances which propagate through the system at the local sonic velocity. With flow passages of the order of meters in length, this gives a time constant of the order of milliseconds. The second category is the spin up of rotary machines such as compressors and turbines. For these small systems the rotational inertia is generally sufficiently small that large RPM changes can be made in the order of seconds or less. The third category is the much slower heat transfer effects within heat exchangers and the steam reformer. Depending on the thermal mass of these devices, one is looking at time constants of the order of seconds to many minutes. Since the slower heat transfer effects determine the response of a PEFC system we will initially concentrate on these effects assuming that the more rapid pressure/mass flow rate changes can be essentially controlled as one desires.

In order to address the issue of the dynamic response of a steam reformer and the PEFC system, the previously developed GPS/GC system code (Kumar, et.al. 1993) has been extended with several dynamic models. The next section describes these models which is followed by a section detailing dynamics of the reformer itself. The last section then discusses the dynamics of a flow turndown for the entire steam reformed PEFC system. 


\section{DISCLAIMER}

This report was prepared as an account of work sponsored by an agency of the United States Government. Neither the United States Government nor any agency thereof, nor any of their employees, makes any warranty, express or implied, or assumes any legal liability or responsibility for the accuracy, completeness, or usefulness of any information, apparatus, product, or process disclosed, or represents that its use would not infringe privately owned rights. Reference herein to any specific commercial product, process, or service by trade name, trademark, manufacturer, or otherwise does not necessarily constitute or imply its endorsement, recommendation, or favoring by the United States Government or any agency thereof. The views and opinions of authors expressed herein do not necessarily state or reflect those of the United States Government or any agency thereof. 


\section{DYNAMIC MODELS}

Therien, et.al. (1987) describe a dynamic steam reformer model for an electrically heated catalyst bed. In actual PEFC systems one will more likely use a hot gas flow to provide for the heats of reaction. Thus a detailed dynamic model has been developed that treats a series of tubes or annular regions filled with a mixture of copper and zinc oxides as catalyst, surrounded by tubes walls, and a hot gas region. Both the radial and axial temperature and species concentrations fields are calculated within the catalyst tubes and hot gas regions.

Since the main thrust of the model is to examine the thermal response of the reformer, some simplifying assumptions have been made concerning the flow fields. First, it is assumed that the flow field is fully developed. Second, the pressure drops are considered to be negligibly small relative to the inlet pressures. With these two assumptions, the velocity fields can be calculated from the overall conservation of mass equation alone without the use of the conservation of momentum equations. The density is determined from the equation of state using the values of pressure, temperature and composition. For both the hot gas region and the flow within the porous catalyst bed the overall conservation of mass equation is

$$
\frac{\partial \rho}{\partial t}+\nabla \cdot(\rho \bar{v})=0
$$

where $\rho$ is the gas density, $v$ is the gas velocity, and $t$ is time. Here the divergence operator is with respect to the cylindrical coordinates attached to the catalyst tube.

Within the catalyst bed the species conservation equation takes the form

$$
\varepsilon \frac{\partial C_{i}}{\partial t}+\varepsilon \nabla \bullet\left(\bar{v} C_{i}\right)=\nabla \bullet\left(D \nabla C_{i}\right)+r_{i} \rho_{b e d}(1-\varepsilon)
$$

where $C_{i}$ is the $i$-th species concentration, $\varepsilon$ is the porosity of the catalyst bed, $\rho_{\text {bed }}$ is the density of the catalyst bed material, $D$ is the species diffusion coefficient, and $r_{i}$ is the source term representing the rate of species creation per kilogram of catalyst. For the hot gas flow frozen chemistry is used; this stream being of lesser importance in that it simply supplies the heat for the process and thus, its speciation is not all that important.

Due to the assumption of constant pressure, the time-dependent conservation of energy equation can be formulated in terms of enthalpy. For the reformate gas, the energy equation is

$$
\begin{gathered}
\varepsilon \frac{\partial}{\partial t}(\rho h)+\varepsilon \nabla \bullet(p \bar{v})=\nabla \bullet\left(\kappa_{\text {ref }} \nabla T_{\text {ref }}\right)+ \\
U A\left(T_{\text {bed }}-T_{\text {ref }}\right)+r(1-\varepsilon) \rho_{\text {bed }} \Delta h_{\text {reac }}
\end{gathered}
$$

where $h$ is the gas enthalpy, $K_{\text {ref }}$ is the thermal conductivity of the reformate, $T_{r e f}$ is the reformate temperature, $T_{\text {bed }}$ is the catalyst temperature, $U$ is the effective particle bed heat transfer coefficient, $A$ is the surface area per volume of catalyst, $r$ is the reaction rate, and $\Delta h_{r e a c}$ is the heat of reaction. By referencing each species enthalpy to the heat of formation of the species the heat of reaction can be defined as

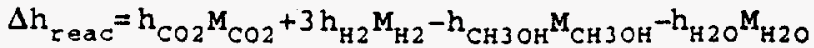

where $M_{i}$ is the molecular weight and $h_{i}$ is the enthalpy of species $i$ in the overall reforming reaction

$$
\mathrm{CH}_{3} \mathrm{OH}+\mathrm{H}_{2} \mathrm{O}=\mathrm{CO}_{2}+3 \mathrm{H}_{2} \text {. }
$$

Note that the heat of reaction term technically should not appear within the energy equation. When formulated in terms of enthalpy, the reaction heat is included here as a modeling assumption. Without this term, all of the endothermic heat of reaction would be extracted from the gas. Since the reactions are heterogeneous, much of the heat should come from the bed particles which are the heat source. We model this by adding back into the gas stream the heat of reaction and at the same time subtracting it from the particle bed energy equation.

The energy equations for the particle bed (subscript bed), catalyst tube walls (subscript wall) and the hot gas (subscript gas) are

$$
\begin{gathered}
(1-\varepsilon) \rho_{\text {bed }} c p_{\text {bed }} \frac{\partial}{\partial t}\left(T_{\text {bed }}\right)=\nabla \bullet\left(\kappa_{\text {bed }} \nabla T_{\text {bed }}\right)+ \\
\operatorname{UA}\left(T_{\text {ref }}-T_{\text {bed }}\right)-r(1-\varepsilon) \rho_{\text {bed }} \Delta h_{\text {reac }} \\
\rho_{\text {wall }} c p_{\text {wal1 }} \frac{\partial}{\partial t}\left(T_{\text {wa1l }}\right)=\nabla \bullet\left(\kappa_{\text {wall }} \nabla T_{\text {wall }}\right) \\
\frac{\partial}{\partial t}(\rho h)+\nabla \bullet(\rho \overline{v h})=\nabla \bullet\left(\kappa_{\text {gas }} \nabla T_{\text {gas }}\right) .
\end{gathered}
$$

An additional option is also provided in which a common reformate and catalyst particle temperature is calculated from the following combined equation.

$$
\begin{array}{r}
\frac{\partial}{\partial t}\left[(1-\varepsilon) \rho_{\text {bed }} c p_{\text {bed }} T+\varepsilon \rho_{\text {ref }}\left(c p_{r e f} T+h_{0}\right)\right]+ \\
\nabla \cdot\left(\bar{v} \varepsilon p_{\text {ref }}\left(c p_{z e f} T+h_{0}\right)\right)=\nabla \cdot(\kappa \nabla T)
\end{array}
$$

Here the reformate enthalpy has been represented as $c p ~ T+h_{0}$, and the enthalpy of each species as $h_{i}=c p_{i} T+h_{0 i}$, where

$$
c p=\sum Y_{i} c p_{i} \text { and } h_{0}=\sum Y_{i} h_{0 i}
$$

and $y_{i}$ are the species mass fractions. This energy equation along with the ones for the walls and hot gas are solved simultaneously to determine the temperature field throughout the reformer.

Note that the thermal conductivities used in the above equations for the fluid flows are actual effective conductivities enhanced by a factor to account for the fluid motion. This is done by calculating an effective Nusselt number for the flow and enhancing the thermal conductivity by that number.

The reaction rates $r_{i}$ and $r$ appearing in the conservation equations are taken from the experimental work of Amphlett, et.al. (1985-1988) and Jiang, et.al. (1993). These papers present a number of reaction mechanisms and reaction rates for several different commercial catalysts. While all of the different catalytic reaction rates have been implemented within the code, as well as several different options concerning the treatment of the water gas shift reaction, we used only the $\mathrm{Cl} 8 \mathrm{HC}$ catalyst in these studies. For the 
methanol decomposition reaction using the $\mathrm{C} 18 \mathrm{HC}$ catalyst, the reaction rate $\mathrm{r}_{\mathrm{CH} 3 \mathrm{OH}}$ is defined by the equations

$$
\begin{gathered}
-\mathrm{r}_{\mathrm{CH} 3 \mathrm{OH}}=k_{\mathrm{CH} 3 \mathrm{OH}}\left(c_{\mathrm{CH} 3 \mathrm{OH}}-\mathrm{C}_{\mathrm{CO}} \mathrm{C}_{\mathrm{H} 2}^{2} / \mathrm{K}_{\mathrm{eq}}\right) \\
\mathrm{k}_{\mathrm{CH} 3 \mathrm{OH}}=8.06 \times 10^{5} \exp (-10100 / \mathrm{T}) . \\
\mathrm{k}_{\mathrm{eq}}=4.275 \times 10^{14} \exp (-11160 / \mathrm{T}) .
\end{gathered}
$$

In addition to the dynamic reformer model, a dynamic heat exchanger model was also added to the GPS/GC systems code. For use in system studies a fast running model was developed using only the inlet and exit flow temperatures and the wall temperatures at the inlet and exit regions. The set of differential equations used to represent the conservation of energy within the fluid flows are as follows.

$$
\begin{gathered}
\rho_{c} \frac{\partial h_{c 1}}{\partial t}=m_{c}\left(h_{c 0}-h_{c 1}\right)+U_{c} A \Delta T_{w c} \\
\rho_{h} \frac{\partial h_{h 1}}{\partial t}=m_{h}\left(h_{h o}-h_{h 1}\right)-U_{h} A \Delta T_{h w}-\sum_{i=0}^{1} \sigma \varepsilon \frac{A}{2}\left(T_{h i}^{4}-T_{w i}^{4}\right)
\end{gathered}
$$

In these equations, the subscripts $c$ and $h$ refer to the cold and hot flows respectively, $w$ refers to the wall, and 0 and 1 to the inlet and exit conditions; $V$ is the fluid flow volume, $m$ is the mass flow rate, $\Delta \mathrm{T}$ is the $\log$ mean temperature difference, $\mathrm{U}$ is the effective heat transfer coefficient, $A$ is the surface area for heat transfer, $\sigma$ is the Stefan-Boltzmann constant and $\varepsilon$ is the effective emissivity of the wall surface. For the radiant heat transfer the local heat flux at the two ends, calculated based on the hot fluid temperatures and the wall temperatures at the two ends, is used over half the total heat transfer surface area.

The wall temperatures at the two ends, $T_{w 0}$ and $T_{w 1}$, are determined from the following energy conservation equation,

$\frac{M_{w}}{2} C p_{w} \frac{\partial T_{w i}}{\partial t}=U_{h} A \Delta T_{h w} E_{h i}+\sigma \varepsilon \frac{A}{2}\left(T_{h i}^{4}-T_{w i}^{4}\right)-U_{c} A \Delta T_{w i} f_{c i}$. where $i=0$ or 1 . Here $M_{w}$ is the total mass of the wall material and the $f$ 's are weights used to partition the heat transfer such that it is proportional to the temperature difference at each end.

In the above equations, $\Delta T$ is dependent on both end point temperatures of one of the fluid flows and the wall. For the normal case of the hot flow being hotter than the wall at both ends the log mean temperature is defined as

$$
\Delta T_{h w}=\frac{\left(T_{h 0}-T_{w 0}\right)-\left(T_{h 1}-T_{w 1}\right)}{\ln \left(\left(T_{h 0}-T_{w 0}\right) /\left(T_{h 1}-T_{w 1}\right)\right)}
$$

This cannot be used, however, for a temperature crossover situation (where the temperature differences are of opposite sign at the two ends) which can occur in a dynamic case due to the changing inlet flow temperature. In such a situation the actual heat transfer along the fluid flow path is both positive and negative. However, such situations are generally short-term transients and thus, $\Delta T_{h w}$ is adjusted to approximately represent the driving temperature difference and, more importantly, to qualitatively represent the way the temperature fields would change in such a crossover situation. This adjustment essentially makes the sign of the log mean temperature difference the same as the temperature difference at the exit. Moreover, the weights, $f_{i}$ used in the wall energy equations are adjusted so that the main heat transfer is shifted downstream during a crossover transient.

\section{DYNAMIC REFORMER STUDIES}

While a number of validation and steady-state studies were done with the reformer model, here we report on some cold startup transients using two different catalyst tube diameters.

The start-up of the reformer may be one of the greatest disadvantages of a steam-reformed PEFC system. In particular the energy usage in bringing the reformer catalyst to a temperature such that good methanol conversion is obtained can easily cause several percentage point penalty on the overall system efficiency, depending on the operational time. For example, the overall efficiency can be defined as

$$
\eta_{\text {overall }}=\frac{P_{\text {out }} t_{\text {op }}}{\left(P_{\text {out }} \eta_{\text {sys }}\right) t_{\text {op }}+E_{\text {start }}}
$$

where $P_{\text {out }}$ is the output power, $t_{o p}$ is the operational time, $\eta_{\text {sys }}$ is the steady-state system efficiency, and $E_{\text {start }}$ is the start-up energy. The start-up energy can be estimated from the fuel flow rate ( $P_{\text {out }}\left(\eta_{\text {sys }} L H V\right)$, LHV is the lower heating value of the fuel), the catalyst to fuel flow rate ratio, $W / F$, the specific heat of the catalyst bed, $C_{p}$, and the temperature rise to design conditions, $\Delta T$,

$$
E_{\text {start }}=\frac{W}{F \eta_{\text {sys }} \text { LIFV }} C_{p} \Delta T
$$

Figure 1 shows a plot of $\eta_{\text {overaly }} \eta_{\text {sys }}$ as a function of $t_{o p}$ for $C_{p}$ of $1100 \mathrm{~J} / \mathrm{kg}-\mathrm{K}, \Delta \mathrm{T}$ of $200 \mathrm{~K}$, and LHV of $639 \mathrm{~kJ} / \mathrm{mole}$ for different W/F values (kg-s/mole). As can be seen it takes roughly $1200 \mathrm{~s}$ of operation to give an overall efficiency of $90 \%$ that of the steady-state value and even these results are optimistic since we have neglected the thermal mass of the tube walls. Note that the efficiency penalty, as estimated, is independent of the start-up time.

As a first dynamic study of the reformer a ramp-up from cold conditions was examined in which the hot gas temperature was raised from a nominally cold $(300 \mathrm{~K})$ flow to design flow $(900 \mathrm{~K})$ in $1 \mathrm{~s}$ and the water/fuel mixture temperature was raised from a nominally cold flow to design flow level at $400 \mathrm{~K}$ in $60 \mathrm{~s}$. The design flow rates were such that the hot gas to reformate flow ratio was 3.2. Two different catalyst tube diameters were considered. The first was $5 \mathrm{~cm}$ in diameter with a catalyst to fuel ratio, $W / F$, of $600 \mathrm{~kg}-\mathrm{s} / \mathrm{mol}$ and the second was $2 \mathrm{~cm}$ with a W/F of $300 \mathrm{~kg}-\mathrm{s} /$ mole. The steady-state design methanol conversions for both of these catalyst tubes were well over $99 \%$. Figure 2 shows the methanol conversion as a function of time for these two cases. A substantial improvement in start-up conversion is gained in going to the smaller tube diameter. This is primarily due to the improved 
heat transfer to the catalyst from the hot gas flow with the smaller tube. Figures 3 and 4 show the temperature histories of the catalyst bed peak temperature (bed max), and the reformate (ref exit) and hot gas exit temperatures for these two cases. While the peak bed temperatures have nearly reached their design levels, the exit temperatures are still rising after $1500 \mathrm{~s}$ and have some way to go before reaching their steady-state values. The plateau in the peak temperature is due to the bed reaching the inlet reformate temperature at the inlet and remaining at that temperature until the peak location moves slightly downstream as more heat is delivered by the hot gases.

When heated by a hot gas flow, as opposed to the electrical heating done in experiments, the catalyst bed tends to heat up from the inlet to the exit. Figure 5 shows the gradual heat up as a function of axial location at selected times for the $2 \mathrm{~cm}$ tube.

In order to further improve the start-up speed another scenario was analyzed in which the hot gas flow rate was linearly ramped up to 3 times the design rate and to $1200 \mathrm{~K}$, held there for the next 180 $\mathrm{s}$, at which point, it was ramped down to $900 \mathrm{~K}$ at the design flow rate. The fuel/water mixture remained at some small nominal cold flow for the first $180 \mathrm{~s}$ and then ramped up to $400 \mathrm{~K}$ at design flow rate over the next $60 \mathrm{~s}$. Figure 2 shows the start-up conversions in this case (labeled as $3 x$ ). Note that while over $80 \%$ conversion is obtained at $180 \mathrm{~s}$ the flow rate is not at its design level until $240 \mathrm{~s}$. Even so this scenario clearly indicates that very good conversions can be obtained within $300 \mathrm{~s}$. Figure 6 shows the temperature histories for this scenario and the reason the hot gas needed to be ramped down after $180 \mathrm{~s}$, else the bed temperatures would easily exceed $550 \mathrm{~K}$.

\section{DYNAMIC SYSTEM STUDIES}

In this section we look at the problems associated with the dynamic turn-down from design levels of a reference steam-reformed methanol-fueled PEFC system shown in Figure 7 (Kumar et.al, 1993). The turn down problem is important in that, there is a possibility of a overheating the reformer bed and permanently damaging the catalyst.

The system was first run at a design point and sized to produce $80 \mathrm{~kW}$ electric. A number of different turn-down scenarios were then analyzed that differ in the relative rates at which the fuel cell loading conditions change relative to the system flows. As indicated earlier, the assumption was made that the pressures could be maintained at the lower flow rates.

The first turn down scenario is the simplest. The flow rates for both air and fuel are ramped down, such that the rate of increase in load resistance on fuel cell keeps the fuel utilization at a constant $85 \%$. The fresh fuel to the preheater is also ramped off over the first $2 \mathrm{~s}$. The water flow rate is adjusted to maintain the cell temperature at $353 \mathrm{~K}$. Figure 8 shows gas temperatures at the inlet and exit of the reformer and the preheater for a turn-down of flows from $100 \%$ to $50 \%$ of design values in a $10 \mathrm{~s}$ interval. Note that the system is not at a new steady-state at the end of $10 \mathrm{~s}$. As can be seen in Figure 8 , the exit temperature of the reformer (ref tcold out) is still almost exactly the same as at the higher flow rates. This is due to the large heat capacity within the reformer catalyst tubes. For this run the catalyst tubes were $2 \mathrm{~cm}$ in diameter with a design catalyst weight to fuel tlow rate of $331.242 \mathrm{~kg}-\mathrm{s} / \mathrm{gmol}$ of methanol yielding a conversion above $99.9 \%$. As the flow rates are reduced, however, the temperature of the hot gas entering the preheater (pre thot in), is relatively constant after the fresh fuel flow is turned off, but the wated fuel mixture temperature (ref tcold in) at the exit of the preheater has greatly increased from $400 \mathrm{~K}$ at the design point to over $600 \mathrm{~K}$ at $10 \mathrm{~s}$. This temperature is much higher than what the catalyst could tolerate. The problem here is two-fold. The hot gas entering the preheater while having a smaller flow rate is still delivering heat to the walls, and the walls have a sufficiently high thermal mass to maintain the design temperature but are now delivering heat to a much smaller water/fuel mixture. For this study the preheater walls were defined with a density of $8000 \mathrm{~kg} / \mathrm{m}^{3}$ (stainless steel), cp of $600 \mathrm{~J} / \mathrm{kg}-\mathrm{K}$, and a thickness of $1 \mathrm{~mm}$.

In order to control the inlet reformer temperature, system configuration changes were considered in which some of the process water for the reformer came directly from the cold water flow and was mixed in after the preheater. The total water to fuel ratio was kept constant by gradually decreasing the hot process water and increasing the cold water flow from the water tank. After $10 \mathrm{~s} 10 \%$ of the process water for the reformer was supplied by the tank. Figure 9 shows the results of the same $10 \mathrm{~s}$ ramp down from $100 \%$ to $50 \%$ of design flow rates. In this case the addition of the cold water after the preheater easily keeps the reformer inlet water/fuel mixture (ref tcold in) under $460 \mathrm{~K}$.

During the above turn-down scenarios the fuel cell load resistance increase was matched by an appropriate reduction in flow rates such that the fuel utilization was constant. This, in general, will probably not happen in practice. If the fuel utilization were to increase, less fuel would be available to the reformer preheater burner and the hot gas temperature entering the reformer preheater would actually decrease, helping to limit the temperature of the fuel/water mixture entering the catalysts tubes. However, as shown by the above scenarios, the hot gas temperature is not the only factor contributing to the overheating of the catalyst, the heat content within the preheater walls is also important, thus, some form of temperature control will still be needed. If, however, the fuel utilization were to decrease during turn down, then the hot gas temperature entering the preheater could increase dramatically, necessitating a still greater control over the inlet reformer temperature. Figure 10 shows such a scenario, in which the fuel utilization is suddenly dropped from the design level of $85 \%$ to $25 \%$ due to cell loading changes at $1 \mathrm{~s}$ into the run. The utilization is then gradually ramped back up to the design level of $85 \%$ over the next $9 \mathrm{~s}$ as the flow rate is reduced. The previously used cold water mixing with up to $10 \%$ of the process water coming directly from the water tank is also used in this scenario. Additionally, the direct fuel to the preheater burner is also immediately ramped down in $1 \mathrm{~s}$ to zero as the load resistance is changed. As can be seen in Figure 10 the hot gas temperature to the reformer preheater (pre thot in) immediately increases from $1098 \mathrm{~K}$ at full power to over $1700 \mathrm{~K}$ at $25 \%$ fuel utilization. As the flow rates gradually change the temperature further rises above $1800 \mathrm{~K}$ over the next couple of seconds before it begins to decrease as the fuel utilization increases. As a consequence the fuel/water mixture (ref tcold in) entering the catalyst tubes gradually increases to over $635 \mathrm{~K}$ within the first $9 \mathrm{~s}$ and is still increasing. The cold water mixing successfully used to control the inlet 
reformer temperature for the fixed fuel utilization case can no longer compensate for the large increase in hot gas temperature to the preheater. Thus, it becomes imperative to reduce the flow rates as rapidly as possible or at least as fast as load resistance increases to the fuel cell in a turn-down scenario

\section{CONCLUDING REMARKS}

Hybrid PEFC systems are being considered in which conceptually a battery is used for load leveling and the fuel cell is operated at an average steady-state power. Even so, because of variabilities in actual driving cycles, there will be instances when the battery is fully charged and the demand is low so that the fuel cell subsystem must be tumed down. Depending on the rate at which the fuel flow to the reformer is reduced, there is a possibility of overheating the catalyst bed. This study indicates that a water injection between the preheater and the reformer can control the temperature overshoots in many turn-down transients without exceeding the design fuel-towater ratio. However this technique is not effective when the load changes on the fuel cell create rapid reductions in fuel utilizations.

Start-up time from cold is an important performance issue in design of steam-reformed PEFC systems. This study has considered the start-up of the reformer driven by a hot gas flow and has quantified the improvement in start up with narrower catalyst tubes and higher than design hot gas to reformate flow ratio.

\section{REFERENCES}

J.C. Amphlett, M.J. Evans, R.F. Mann, and R.D. Weir, "Hydrogen Production by the Catalytic Steam Reforming of Methanol Part 1: Kinetics of Methanol Decomposition Using Girdler G66B Catalyst," Canadian Journal of Chemical Engineering, Vol 63, Aug 1985.

J.C. Amphlett, R.F. Mann, and R.D. Weir, "Hydrogen Production by the Catalytic Steam Reforming of Methanol Part 1: Kinetics of Methanol Decomposition Using C18HC Catalyst," Canadian Journal of Chemical Engineering, Vol 66, Dec 1988.

J.C. Amphlett, R.F. Mann, C. McKnight, and R.D. Weir, "Production of Hydrogen Rich Gas by Steam Reforming of Methanol over Copper Oxide-Zinc Oxide Catalysts," Proc. 20th IECEC, Miami Beach, Florida, Aug 1985.

C.J. Jiang, D.L. Trimm, andM.S. Wainwright, "Kinetic Study of Steam Reforming of Methanol Over Copper-Based Catalysts," Applied Catalysis A: General, 93, 1993.

R. Kumar, R. Ahluwalia, H.K. Geyer, and M. Krumpelt, "Modeling of Polymer Electrolyte Fuel Cell Systems," Post-Conference Proceeding of the 1993 Annual Automotive Technology Development Contractors Coordination Meeting, Oct 18-21, 1993.

Normand Therien et Patrick Tessier, "Modelisation et Simulation de las Decomposition Catalytique du Methanol dans un Reacteur a Lit Fixe,", Canadian Journal of Chemical Engineering, Vol 65, Dec 1987.

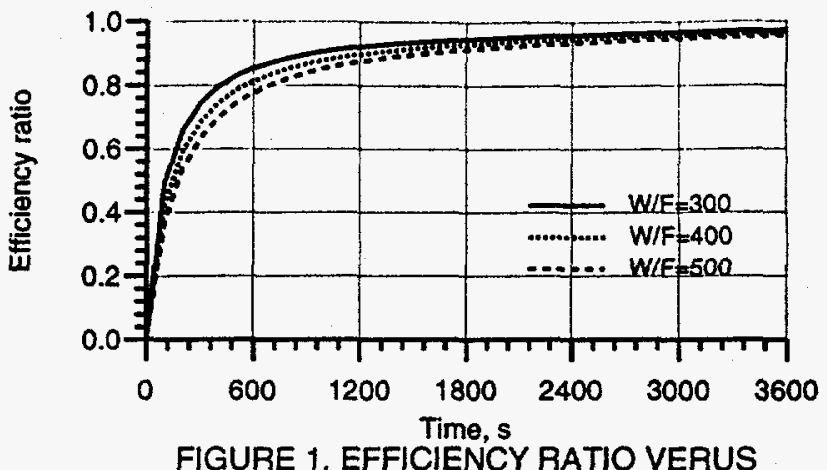

FIGURE 1. EFFICIENCY RATIO VERUS OPERATION TIME AND W/F

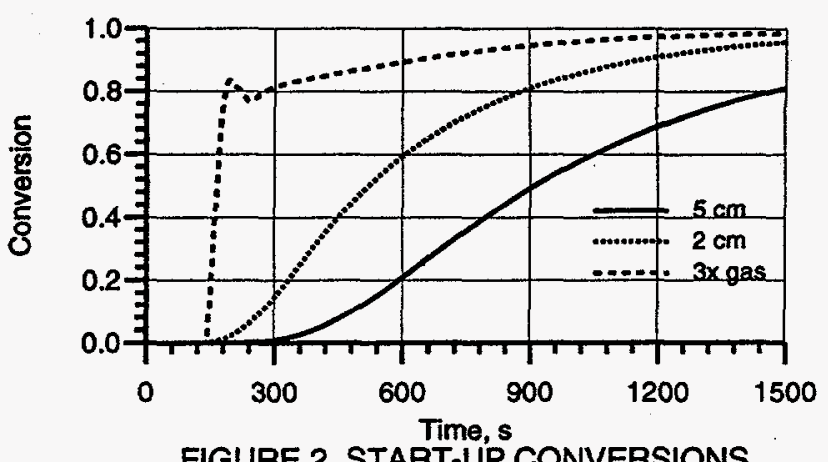

FIGURE 2. START-UP CONVERSIONS

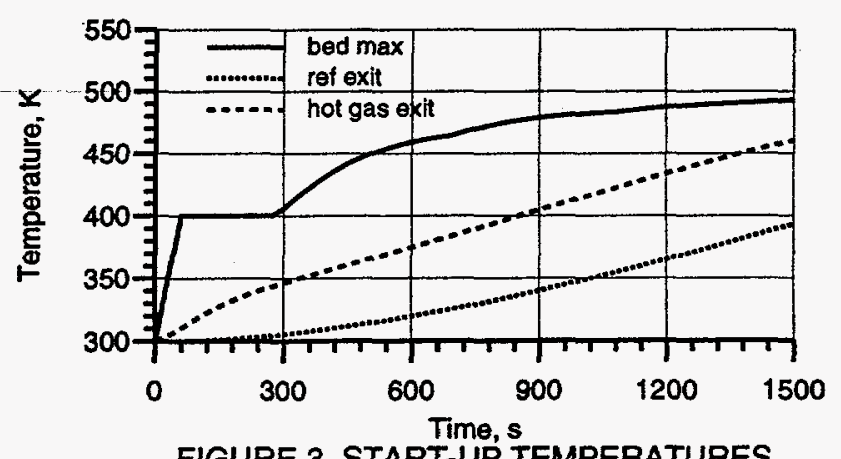

FIGURE 3. START-UP TEMPERATURES FOR A 5-CM DIAMETER REFORMER TUBE

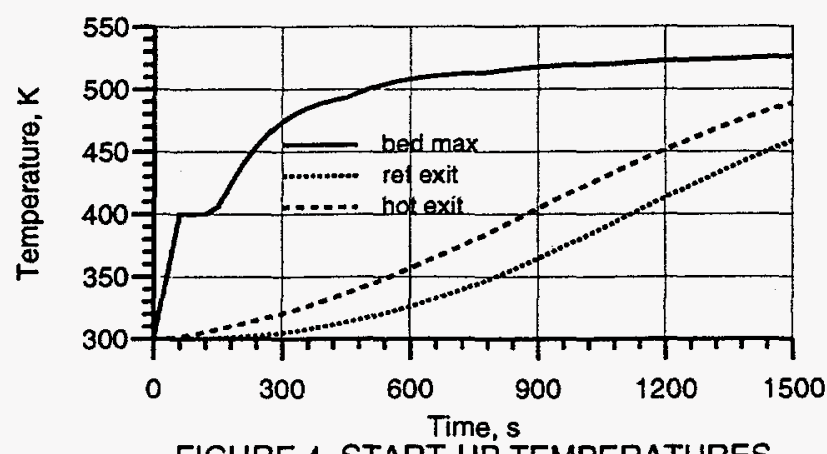

FIGURE 4. START-UP TEMPERATURES FOR A 2-CM DIAMETER REFORMER TUBE 


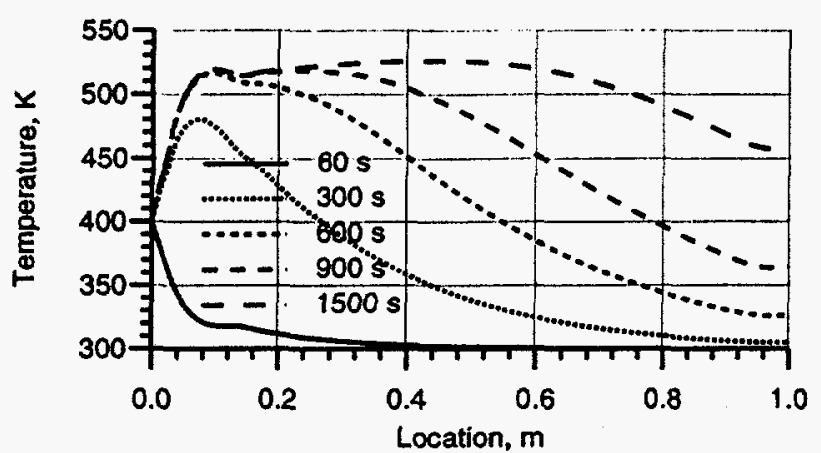

FIGURE 5. START-UP TEMPERATURE

PROFILES FOR A 2-CM REFORMER TUBE

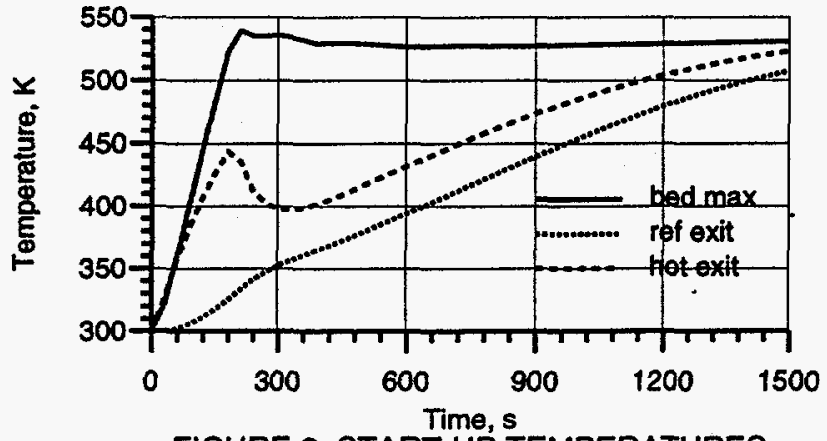

FIGURE 6. START-UP TEMPERATURES FOR A 2-CM REFORMER TUBE WITH $3 X$ HOT GAS FLOW

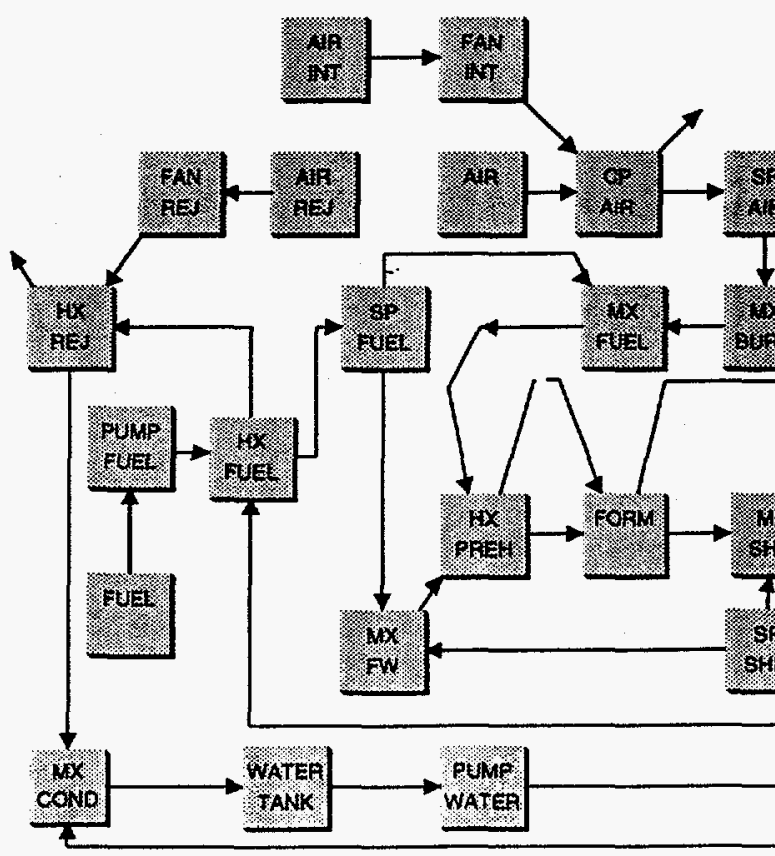

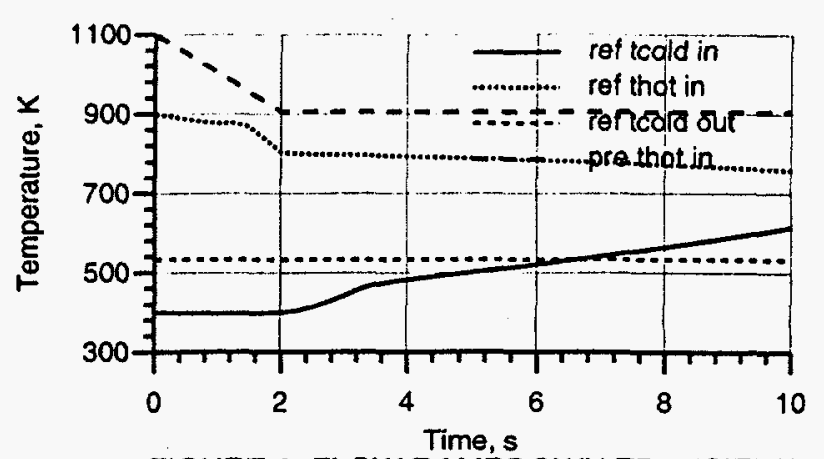

FIGURE 8. FLOW RAMPDOWN TRANSIENT AT CONSTANT FUEL UTILIZATION

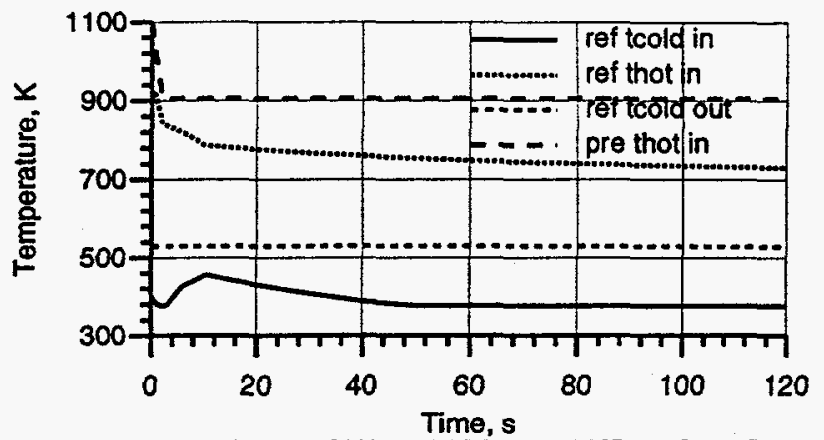

FIGURE 9. FLOW RAMPDOWN TRANSIENT AT CONSTANT FUEL UTILIZATION WITH WATER QUENCH

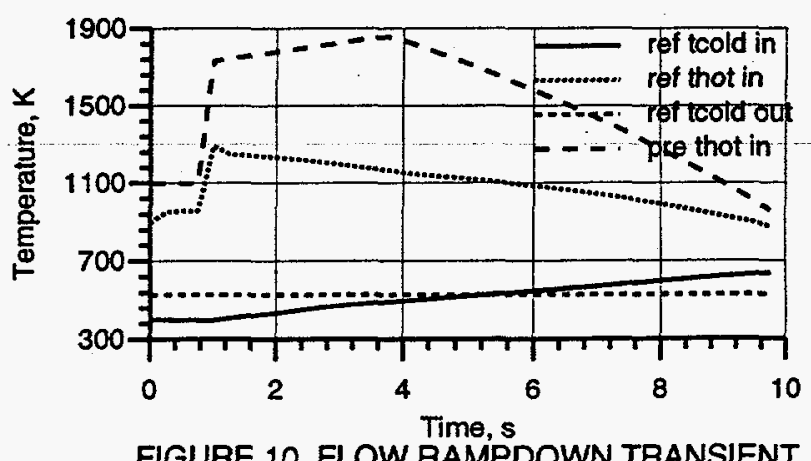

FIGURE 10. FLOW RAMPDOWN TRANSIENT AT NON-CONSTANT FUEL UTILIZATION

FIGURE 7. BASE CASE SYSTEM CONFIGURATION 